\title{
Is heart failure an obstacle to air travel?
}

\author{
Güliz Erdem (D)
}

Department of Cardiology, İstanbul Kent University; İstanbul-Turkey

\section{ABSTRACT}

Rapid increasing trend in air travel brings necessity of urgent approach to health situations such as heart failure (HF). The prevalence of HF was projected to be more than 8 million patients $\geq 18$ years of age in 2030; Main factors that contribute to physiological changes to cardiovascular system during a flight are changes in cabin pressure, humidity, stress, prolonged mobility. Identifying patients at risk of pre/post and during air travel along with adequate care by physicians and crew would help in better outcomes and comfortable travel for patients with HF.

Keywords: air travel, heart failure, flight

\section{Introduction}

Air travel is increasing rapidly and according to the predictions of the International Air Transport Association (IATA), passenger numbers could double to 8.2 billion by 2037. This increasing trend brings the necessity of an urgent approach to important health situations that can be affected by air travel (1). There has also been an ever-increasing rate of use of air medical transport services, provided by insurance-affiliated and private companies, during last 2 decades (2).

In a study, "Update of Heart Disease and Stroke Statistics" published in 2019, the prevalence of heart failure (HF) was projected to be more than 8 million patients $\geq 18$ years of age in 2030 (3). There is not enough guidance on how to deal with patients with HF. There is an urgent need for guidelines for physicians, patients, and air travel agents.

\section{Changes during air travel}

Understanding the physiological changes during a flight is essential (4). Some of the main factors that can affect the cardiovascular system during air travel are decrease of atmospheric pressure, prolonged immobility, decrease in humidity, and both physical and emotional stress.

\section{Effects of cabin pressure}

One of the effects of change in cabin pressure on travelers is hypobaric hypoxia. In a commercial flight, the cabin pressure is equivalent to that of an altitude of 1,524 to $2,134 \mathrm{~m}(5,6)$. At the maximum permitted cabin altitude of $2,438 \mathrm{~m}$ by international regulations, the oxygen saturation may reduce to around $93 \%$ in healthy individuals. Comorbidities such as chronic obstructive pulmonary disease, pulmonary hypertension, chronic renal disease, anemia, and thrombophilia, which could contribute to the reduction in partial pressure of oxygen, are generally associated with $\mathrm{HF}(7)$.

Compressed atmospheric air is routed to the cabin by most aircrafts, and the cabin is pressurized to an atmospheric pressure, usually about 7,500 feet that is only $25 \%$ lower than sea level. It causes $30 \%$ decrease in partial pressure of inspired oxygen and can usually be well compensated by increasing the heart rate and tidal volume in healthy individuals. However, if higher altitudes are needed during turbulence and adverse weather, cabin pressure falls further. If the cabin altitude increases over 10,000 feet, use of supplemental oxygen is advised for all the passengers and cabin crew. However alongside that, it should also be kept in mind that the cabin altitude should be maintained 8,000 feet or less when refering to commercial air travel. Passengers with $\mathrm{HF}$ are especially vulnerable to increasing hypoxemia, which can lead to increase in systemic blood pressure, heart rate, and myocardial contractility, in addition to increase in the pulmonary vascular beds and pulmonary artery pressure (4). According to Operation Everest, hypoxemia, secondary to altitude, leads to changes that can be of potential concern to patients with HF, such as decline in stroke volume, increase in the atrial component of ventricular filling, and increase in pulmonary vascular resistance (8). 
However, pulmonary vasoconstriction may have a role to play in protecting pulmonary microvasculature from increased pressure and decrease in systemic vascular resistance caused by hypoxia; increases in pulmonary and left ventricular pressures may be limited (9). Cabin pressure also affects gas in the body cavities. With increasing altitude, cabin pressure decreases causing an expansion of gas trapped in body cavities up to $30 \%$. For patients with right-sided HF in whom abdominal bloating is a common complaint, intestinal gas expansion could result in additional discomfort. Gas-producing foods should be avoided in the days before and during the flight (10).

\section{Humidity}

At flight altitude, atmospheric air used to pressurize the cabin has very low humidity $(<1 \%)$. However, relative humidity is generally between $5 \%$ and $25 \%$ in the cabin because of other sources of moisture such as food preparation, human respiration, and beverage consumption. Even so, dehydrating beverages, such as coffee and alcohol, should be avoided. Low humidity, especially in prolonged flights, in addition to diuresis promoted by alcohol and coffee, may cause dehydration. Patients with HF should avoid drinking these beverages and drink adequate amounts of water, especially if they are using diuretics, as they are more prone to fluid-electrolyte imbalance $(4,10)$.

\section{Stress}

Air travel is stressful for most people physically and psychologically. Carrying luggage for long distances, access to the airport, long delays at security, check in, and boarding can be difficult. It can be also psychologically stressful for passengers who have anxiety before and during a flight, especially at take-off and landing (11). It was shown that patients with HF with high anxiety levels have shorter event-free survival than patients with low anxiety levels (12). In short-duration round trips, combined with the tiredness of preflight activities such as carrying heavy baggage and walking long distances to gates, the anxiety of patients with HF causes increase in sympathetic activation resulting in increase in heart rate, blood pressure, and systemic vascular resistance that may result in cardiac decomposition (10).

\section{Prolonged immobility}

Prolonged immobility is a risk factor for venous thromboembolism. Chronic HF is also a risk factor because of slow and abnormal flow patterns in poorly contracting, dilated cardiac chambers that causes venous stasis resulting in mural thrombus (13). According to aerospace medical guidelines, uncontrolled $\mathrm{HF}$ is a moderate risk for deep vein thrombosis (14).

\section{Importance of stages of heart failure for air travel}

In a survey among patients who had air travel after HF diagnosis, $65 \%$ did not have any health problems. If present, most health problems were reported at the final destination $25 \%$ of patients) than during the flight ( $9 \%)$. Of the patients who experienced them, $25 \%$ had cardiovascular issues such as palpitations, angina, fatigue, breathlessness, swollen ankles, and firing of their defibrillator (15). Patients with chronic HF and left ventricular ejection fraction $<40 \%$, in New York Heart Association class II-III, and stable on treatment could tolerate a level of hypoxia ( $15 \%$ oxygen) similar to during a flight on a commercial aircraft for 1 hour, without provoking any symptoms, even though arterial oxygen saturation fell to $86 \%$. In this patient group, blood pressure and systolic pulmonary artery pressure increased significantly without any change in cardiac output along with a fall in left ventricular filling pressure (16).

In 2010, Smith et al. (9) published a report titled, "Fitness to fly for passengers with cardiovascular disease" according to which, short-term hypoxia (of up to 1 hour) did not cause any significant deleterious effects in patients with stable HF, even if they were NYHA class III and IV. Patients with stable and mild to moderate (class II) HF could tolerate periods up to 7 hours. In chronic HF, if there has not been a recent change in medication or symptoms, mild hypoxia is generally well tolerated. For patients who are severely limited (NYHA class IV), in-flight oxygen is advised.

Acute HF is mainly caused by acute coronary syndrome or can be precipitated by an infection or anemia on a background of chronic left ventricular dysfunction. After treatment of the acute episode and underlying factors, patients are generally stabilized in 6 weeks and ready to fly safely (9). It is recommended that air travel should be avoided in patients with decompensated HF. If flying cannot be avoided, in-flight oxygen is a must (17). For such patients, there should be experienced and qualified personnel on board along with appropriate medical equipment and the right aircraft $(9,10)$.

\section{Conclusion}

With increase in the HF population and preference for air travel globally, more information about and attention to this particular patient group is needed. Identifying patients at risk of pre/ post and during air travel along with adequate care by physicians and crew would help in better outcomes and comfortable travel for patients with HF.

Conflict of interest: None declared.

\section{References}

1. Available from: URL: https://www.iata.org/en/pressroom/pr/201810-24-02/

2. Essebag V, Halabi AR, Churchill-Smith M, Lutchmedial S. Air medical transport of cardiac patients. Chest 2003; 124: 1937-45. [Crossref]

3. Benjamin EJ, Muntner P, Alonso A, Bittencourt MS, Callaway CW, Carson AP, et al.; American Heart Association Council on Epidemiology and Prevention Statistics Committee and Stroke Statistics Subcommittee. Heart Disease and Stroke Statistics-2019 Update: A Report From the American Heart Association. Circulation 2019; 139: e56-528. 
4. Hammadah M, Kindya BR, Allard-Ratick MP, Jazbeh S, Eapen D, Wilson Tang $W H$, et al. Navigating air travel and cardiovascular concerns: Is the sky the limit? Clin Cardiol 2017; 40: 660-6. [Crossref]

5. Certification Specifications for Large Aeroplanes CS-25 Section No. 841 [Regulatory document; ED de- cision No. 2003/2/RM]. Cologne, Germany: Euro- pean Aviation Safety Agency; 2003. Available from: URL: http://www.easa .eu.int/doc/Agency_ Mesures/Certification_Spec/decision_ED_2003_02_RM.pdf.

6. Airworthiness Standards: Transport Category Air- planes [design and construction: pressurization], 14 USC \$25.841 (2004). Available from: URL: https://www.govregs.com/regulations/expand/title14_chapterl_ part25_subpartD_subjgrp102_section25.899\#regulation_0_0

7. Toff WD, Jones Cl, Ford I, Pearse RJ, Watson HG, Watt SJ, et al. Effect of hypobaric hypoxia, simulating conditions during long-haul air travel, on coagulation, fibrinolysis, platelet function, and endothelial activation. JAMA 2006; 295: 2251-61. [Crossref]

8. Boussuges A, Molenat F, Burnet H, Cauchy E, Gardette B, Sainty JM, et al. Operation Everest III (Comex '97): modifications of cardiac function secondary to altitude-induced hypoxia. An echocardiographic and Doppler study. Am J Respir Crit Care Med 2000; 161: 264-70. [Crossref]

9. Smith D, Toff W, Joy M, Dowdall N, Johnston R, Clark L, et al. Fitness to fly for passengers with cardiovascular disease. Heart 2010; 96 Suppl 2: ii1-16. [Crossref]
10. Izadi M, Alemzadeh-Ansari MJ, Kazemisaleh D, Moshkani-Farahani M. Air travel considerations for the patients with heart failure. Iran Red Crescent Med J 2014; 16: e17213. [Crossref]

11. Joy M. Cardiovascular disease and airline travel. Heart 2007; 93 : 1507-9. [Crossref]

12. De Jong MJ, Chung ML, Wu JR, Riegel B, Rayens MK, Moser DK. Linkages between anxiety and outcomes in heart failure. Heart Lung 2011; 40: 393-404. [Crossref]

13. Heit JA, Silverstein MD, Mohr DN, Petterson TM, O'Fallon WM, Melton LJ 3rd. Risk factors for deep vein thrombosis and pulmonary embolism: a population-based case-control study. Arch Intern Med 2000; 160: 809-15. [Crossref]

14. Aerospace Medical Association Medical Guidelines Task Force. Medical Guidelines for Airline Travel, 2nd ed. Aviat Space Environ Med 2003; 74 (5 Suppl): A1-19.

15. Ingle L, Hobkirk J, Damy T, Nabb S, Clark AL, Cleland JG. Experiences of air travel in patients with chronic heart failure. Int J Cardiol 2012; 158: 66-70. [Crossref]

16. Hobkirk JP, Damy T, Walters M, Bennett A, Smith SJ, Ingle L, et al. Effects of reducing inspired oxygen concentration for one hour in patients with chronic heart failure: implications for air travel. Eur $\mathrm{J}$ Heart Fail 2013; 15: 505-10. [Crossref]

17. Ahmedzai S, Balfour-Lynn IM, Bewick T, Buchdahl R, Coker RK, Cummin AR, et al.; British Thoracic Society Standards of Care Committee. Managing passengers with stable respiratory disease planning air travel: British Thoracic Society recommendations. Thorax 2011; 66 Suppl 1: i1-30. [Crossref] 